\title{
Rhéologie particulière des solutions de polymères en milieu poreux
}

\author{
Par C. Thirriot et G. Massarani (Rio de Janeiro)
}

Rheol. Acta 13, 791-796 (1974)

p. 792, right column, last eq. at the bottom, read correctly:

$$
v_{m} \sim\left(\frac{\Delta p^{*}}{\Delta x}\right)^{1 / n} \sim \frac{q}{P} .
$$

p. 796, add the following German Summary:

\section{Zusammenfassung}

Die Autoren rufen zunächst einmal die Analogie zwischen porösem Medium und Kapillarbündeln laminarer nichtNewtonscher Strömung in Erinnerung.

Die Betrachtung eines nichtzylindrischen Abflußrohrs hebt die Grenzen der Analogie hervor, wie sie durch eine Formänderung des Diagramms bei Druckverlusten in Funktion der Abflußmenge im Falle eines beliebigen rheologischen Gesetzes gekennzeichnet ist sowie durch eine Affinität im Falle des Modells vom Typus Ostwald-de Waele. In letzterem Falle schlagen die Autoren eine Verallgemeinerung des Gesetzes von Darcy vor.
Dann werden die Ergebnisse von 21 Versuchsreihen vorgelegt, die von sechs Flüssigkeitslösungen von Industrieprodukten handeln: Tylose, MH $2000 \mathrm{~K}$, Tylose C 1000 , Natrasol $250 \mathrm{H}$, Polyox WSR 301, Adragantgummi, Vistanex NML 100. Diese Lösungen durchfließen poröse, künstlich verfestigte Medien, deren Durchlässigkeit von $10^{-7}$ bis $10^{-5}$ pro qcm reicht, und zwar für Porositäten, die zwischen $20 \%$ und $46 \%$ liegen.

Für die Mehrzahl der Versuche wird die Analogie mit dem Kapillarbündel tatsächlich bestätigt. Für die sehr zähflüssigen Lösungen von Tylose $\mathrm{C} 1000$ jedoch sowie für Adragantgummi tritt eine Verminderung der Durchlässigkeit in Erscheinung, besonders beim Ansteigen der Abflußmenge (bereits von Daubeen und Savius erwähnt), welche aber durch die Auswirkung sukzessiver Beschleunigungen und Abbremsungen, bewerkstelligt durch Verengungen und Erweiterungen der Kanälchen des porösen Mediums, keine Erklärung findet. Die Produkte dagegen, welche ein Auftreten von Normaldruck zur Folge haben, weisen keinerlei Unregelmäßigkeit bezüglich des Abflußgesetzes im porösen Medium auf.

Für die Schriftleitung verantwortlich: Dr. W. Meskat, 5090 Leverkusen, Mühlenweg 90a

Anzeigenverwaltung und Verlag: Dr. Dietrich Steinkopff Verlag, 6100 Darmstadt, Saalbaustraße 12, Postfach 1008 Gesamtherstellung: Druckerei Dr. A. Krebs, Hemsbach/Bergstr. und Bad Homburg v. d. H. 